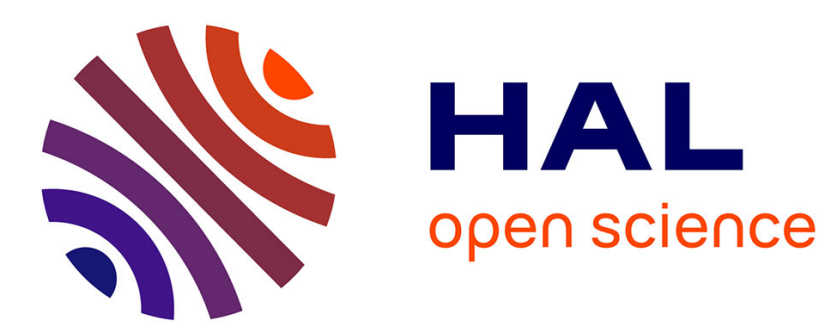

\title{
Anelastic Grain-Boundary Sliding in Ceramics. I. Directly Bonded Polycrystals
}

\author{
K. Ota, G. Pezzotti
}

\section{To cite this version:}

K. Ota, G. Pezzotti. Anelastic Grain-Boundary Sliding in Ceramics. I. Directly Bonded Polycrystals. Journal de Physique IV Proceedings, 1996, 06 (C8), pp.C8-349-C8-352. 10.1051/jp4:1996875 . jpa00254683

\section{HAL Id: jpa-00254683 \\ https://hal.science/jpa-00254683}

Submitted on 1 Jan 1996

HAL is a multi-disciplinary open access archive for the deposit and dissemination of scientific research documents, whether they are published or not. The documents may come from teaching and research institutions in France or abroad, or from public or private research centers.
L'archive ouverte pluridisciplinaire HAL, est destinée au dépôt et à la diffusion de documents scientifiques de niveau recherche, publiés ou non, émanant des établissements d'enseignement et de recherche français ou étrangers, des laboratoires publics ou privés. 


\title{
Anelastic Grain-Boundary Sliding in Ceramics. I. Directly Bonded Polycrystals
}

\author{
K. Ota and G. Pezzotti* \\ Institute of Scientific and Industrial Research, Osaka University, Ibaraki-shi, Mihogaoka 8-1, Osaka 561, \\ Japan \\ * Department of Materials, Kyoto Institute of Technology, Matsugasaki, Sakyo-ku, Kyoto 606, Japan
}

\begin{abstract}
Internal friction of high-purity single-crystal sapphire and three polycrystalline aluminas with different grain sizes has been measured up to very high temperature at the frequency of $10 \mathrm{~Hz}$. Only an exponential background curve was found in the single-crystal while polycrystalline specimens showed a broad anelastic peak, superposed on the background component, whose nature was presumably related to the presence of internal grain boundaries. The overall internal friction curve of the polycrystalline specimens were markedly shifted to lower temperatures as compared to sapphire. The intensity of the grain-boundary peak was decreasing with increasing the grain size. A series of alloys, prepared by doping with increasing amounts of $\mathrm{Cr}_{2} \mathrm{O}_{3}$, were also tested in comparison with ruby single-crystals. The $\mathrm{Cr}$ addition led to both an increase in intensity of the grain-boundary peak and a shift of its maximum towards lower temperatures. This characleristic anelastic behavior was clearly dictated by a lowered coherency of grain boundaries upon Cr alloying.
\end{abstract}

\section{INTRODUCTION}

Internal friction technique is one of the few experimental tools capable to provide direct information about the microscopic diffusive processes occurring either at grain boundaries or within the grains of polycrystalline solids upon increasing temperature. So far, internal friction measurements have been widely and successfully applied to analyze the behavior of both metals and related alloys [1]. Several internal friction studies have also been reported for ceramic polycrystals, mainly in the attempt to phenomenologically relate the damping characteristics to the various processes of strength degradation occurring in polycrystalline solids at high temperature $[2,3]$. However, only a very few evidences have been so far provided about grain-boundary-related internal friction response of polycrystalline ceramics mainly because of the rather high range of temperature needed for performing a meaningful internal friction analysis. One critical issue on the topic also deals with the difficulty in modifying the bond between grains without changing their morphology and bulk deformation behavior.

In this paper we deal with high-purity alumina phase whose boundaries were found to be free from impurities (i.e., directly bonded) up to the resolution allowed by the transmission electron microscope, namely $0.18 \mathrm{~nm}[4]$. It was early recognized that high-purity alumina ceramic with "clean" grain boundary would be an interesting candidate for basic internal friction investigations [5]. This is because it would be relatively easy to obtain significant grain growth without addition of extraneous phases or additives. Furthermore, alumina ceramics undergo a wide range of known solid-solutions which may modify the degree of bonding and coherency of the grain-boundaries. Both this characteristics are examined in the present study.

\section{EXPERIMENTAL PROCEDURE}

Historically, two methods of investigation have been described in the metal field; the first, due to Kêe [6], is the measurement of the anelastic behavior of specimens differing only in the grain boundary area. In other words, upon the occurrence of significant grain growth process, the strength of the anelastic grainboundary peak was found to clearly decrease until disappearing when the grain size was comparable 
with the specimen size or in single crystals. Another approach, widely followed in metals [1], deals with the modification of the grain-boundary bonding through the occurrence of solid solutions.

Four kinds of high-purity aluminium oxide specimens were first tested. They were: three polycrystalline aluminas with different average grain size and one single-crystal sapphire. The polycrystalline specimens were pressureless sintered by the authors using high-purity alumina as a starting powder (Sumitomo AKP-53). Sintering up to full densification was conducted in air with holding the specimens at $1873 \mathrm{~K}$ for 3 hours. Iterative annealing cycles were conducted at $1773 \mathrm{~K}$ for $2-10$ hours in order to produce appreciable grain growth in the polycrystalline body. The average grain sizes of the polycrystalline specimens were found to be 3.3 (in the as-sintered status), 4.8 (for $2 \mathrm{~h}$ annealing) and $19.3 \mu \mathrm{m}$ (for $10 \mathrm{~h}$ annealing). One large, high-purity ( $>99.99 \%)$ single-crystal sapphire rod was purchased from Nakazumi Crystal Co. and cut in suitable dimensions with the c-axis of the crystal nearly parallel to the specimen axis (i.e., the axis of torsion). Annealing for two hours at $1973 \mathrm{~K}$ was then performed in order to release eventual residual stresses induced by machining.

Polycrystalline alumina specimens containing $0.1,0.5,1.0$ and $5.0 \mathrm{wt} \% \mathrm{Cr}$, respectively, were also prepared by hot pressing at temperatures in the range $1723-1823 \mathrm{~K}$ for $2 \mathrm{~h}$, under $30 \mathrm{MPa}$. The hotpressing temperature was empirically optimized in order to achieve nearly full density and a close grain size and morphology (i.e., equiaxed grains 4-6 $\mu \mathrm{m}$ in size) in the four specimens. For comparison, also two ruby crystals were tested. Their Cr content was 0.3 and $3.0 \mathrm{wt} \%$, respectively. The annealing procedure was the same as that described for the sapphire crystal.

Internal friction data were automatically collected at intervals of $5 \mathrm{~K}$, according to the free-decay method [1]. Experiments were conducted at the fixed frequency of $10 \mathrm{~Hz}$. The maximum applied torsional stress was $\approx 10 \mathrm{MPa}$. In order to achieve very high temperatures, the torsional pendulum apparatus was equipped with a carbon heater, rolled around the specimen, and an infrared thermo-analyzer [7]. Preliminary blank-test calibrations by strain gauges were performed to minimize the residual strains in the fixed bottom grip and the extension shaft of the pendulum. Internal friction could be ultimately measured up to the melting point of sapphire, found to be in agreement with the value $\approx 2323 \mathrm{~K}$ reported in previous literature [8].

\section{RESULTS AND DISCUSSION}

Figure 1 shows the internal friction curves of high-purity alumina polycrystals with various grain sizes, $\mathrm{d}$, as a function of the absolute temperature, T. For comparison, also the internal friction curve measured in single-crystal sapphire is reported. Very small, if any, relaxation peak was found in the sapphire rod, its damping curve being simply represented by an exponential-like background. The background curve of sapphire was rising very slowly up to about $10 \mathrm{~K}$ below the melting point, above which a steep rise occurred. The curves of the polycrystals resulted markedly shifted towards lower temperatures, the lower the temperature, the smaller the grain size. It could be argued that the anelastic response of the specimen was directly related to the amount of grain-boundary surface area present in the specimen. Focussing only on the phenomena related to the presence of grain boundaries, the exponential (plastic) background curve found for the sapphire rod can be subtracted from those of the polycrystals. It was thought that, by doing so, the remaining component of internal friction of the polycrystals would represent the anelastic contribution of grain boundaries. A broad peak is revealed by such a procedure as shown, for example, for the polycrystalline alumina with smaller grain size in Fig.2. It is interestingly found that the anelastic peak tends to disappear at larger values of grain size. This evidence, consistent with early studies by $\mathrm{Ke}$ [5] on pure aluminum, appears to provide experimental foundation for relating the origin of the peak to slip at grain boundaries of alumina ceramics.

Figure 3 shows the internal friction curves of two ruby sigle-crystals and a series of $\mathrm{Cr}$-doped alumina polycrystals as a function of the absolute temperature. For an easier comparison, the data for the sapphire specimen from Fig.1 are also replotted. Again no peak was clearly detected in the ruby single crystals, the background curves rising quite slowly up to very high temperature. The temperature from which the steep rise took place was function of the $\mathrm{Cr}$ content, the higher the content the higher the temperature. In the polycrystalline specimens, the increasing additions of $\mathrm{Cr}$ have the double effect of shifting the internal friction curve towards lower temperatures and increasing its absolute value as compared to the pure alumina polycrystal with the same grain size. The former characteristic cannot be dictated by the bulk behavior of the grains, since it reflects exactly the opposite trend as found for the single crystal specimens. Also, any diffusional (i.e., intragranular) origin of the peak is to be $a$ priori excluded since, otherwise, we should be able to monitor it also in the single crystals. Hence, the evolution of the internal friction curve upon $\mathrm{Cr}$ addition should be related to a somehow modified structure of the grain boundary. The relaxation peaks, as a function of $\mathrm{Cr}$ content, are shown in Fig.4 after subtracting the respective exponential backgrounds. The effect of solid-solution by $\mathrm{Cr}$, as discussed above, is best seen in this figure. The apparent activation energy for the present anelastic relaxation peak de- 
creases as the material becomes more $\mathrm{Cr}$-rich. The apparent activation energy values, as calculated from the peak width method [1], were found to be 243,234, 176 and $121 \mathrm{~kJ} / \mathrm{mol}$ for the $0.1,0.5,1.0$ and 5.0 wt\% $\mathrm{Cr}$-doped polycrystals, respectively. Although the present activation energy values may be underestimated because of broadening of the peak, the value found for low $\mathrm{Cr}$-doped material is close to that reported for grain-boundary diffusion in pure alumina polycrystals [9]. Read and Shockley [10] have proposed that, in metallic materials, the unit mechanism in the process of stress relaxation across a directly bonded grain boundary is the transfer of atoms from one edge dislocation to another. In such a process the generation of a vacancy at an edge dislocation results to be the rate-limiting process. Unfortunately, the present data do not allow us to judge whether or not this theory is directly applicable to the present ceramic materials. Furthermore, it is not straightforward how an isovalent solute like as $\mathrm{Cr}$ in alumina can ease vacancy generation. From the present data, it seems to follow that the increase of nominal amount of $\mathrm{Cr}$ atoms in the material involves easier sliding of the grain boundaries. In fact, both the higher intensity and the increased broadness of the peak as well as its lowered peak-top temperature (cf. Fig.4) suggest that grain-boundary sliding occurs in a statistically higher number of boundaries when $\mathrm{Cr}$ content increases. In absence of a glassy phase of finite thickness at the grain boundary [3], the present results would suggest that the presence of $\mathrm{Cr}$ may lead to a modified structure, namely to a lower coherency, of grain boundaries in alumina ceramics.

\section{Acknowledgment}

The authors gratefully thank Prof. T. Nishida for his continuous advice during the course of the present work.

\section{References}

1. Nowick A.S. and Berry B.S., Anelastic Relaxation in Crystalline Solids (Academic Press, New York 1972).

2. Mosher D.R. and Raj R., Acta Metall. 22 (1974) 1469-1474.

3. Lakki A. and Schaller R., "Damping due to grain boundary sliding in zirconia and alumina", to appear in: Inter. Symp. on M3D III: Mechanics and mechanisms of material damping, Norfolk, Virginia, 1995, V.K. Kinra and A. Wolfenden Eds. (ASTM STP 1304).

4. Ota K. and Pezzotti G., Scripta Mater. 34 (1996) 1467-1472.

5. Huber R.J., Baker G.S. and Gibbs P., J. Appl. Phys. 32 (1961) 2573-2581.

6. Kế T.-S, Phys. Rev. 71 (1947) 533-543.

7. Matsushita K., Okamoto T., and Shimada M., J. Phys. C 10 (1985) 349-353.

8. Ochadlick, Jr., A.R., Solid State Ionics 3/4 (1981) 79-85.

9. Cannon R.M. and Coble R., in Deformation of Ceramic Materials, edited by R.C. Bradt and R.E.

Tressler (Plenum, New York, 1975) p.613-621.

10. Read W.T.and Shockley W., Phys. Rev. 78 (1950) 275-286.

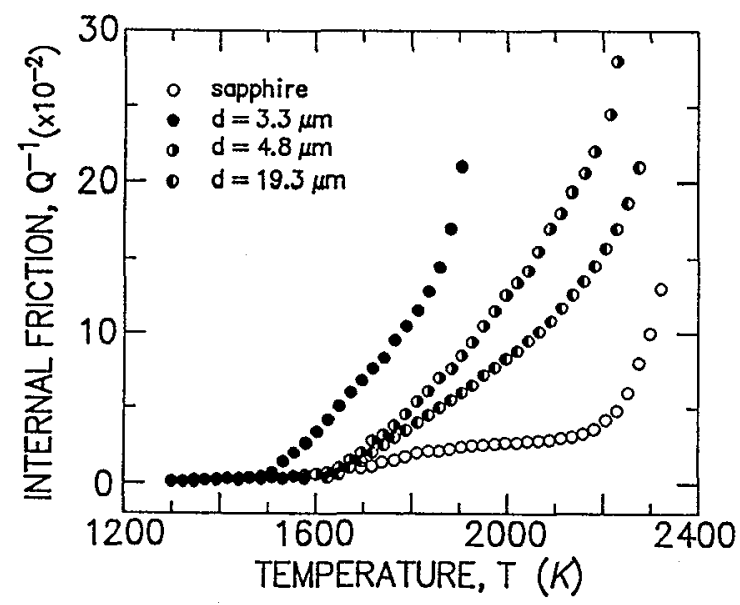

Figure 1: Intcrnal friction curves of single-crystal sapphire and three polycrystalline aluminas with different grain sizes. 


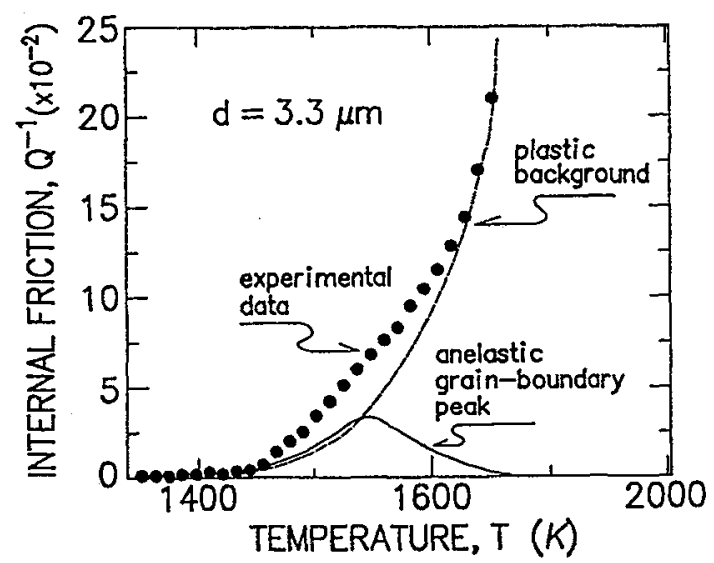

Figure 2: Broad grain-boundary relaxation peak for pure polycrystalline alumina with fine grain size, as revealed by subtracting the exponential-like (plastic) background of the sapphire specimen.

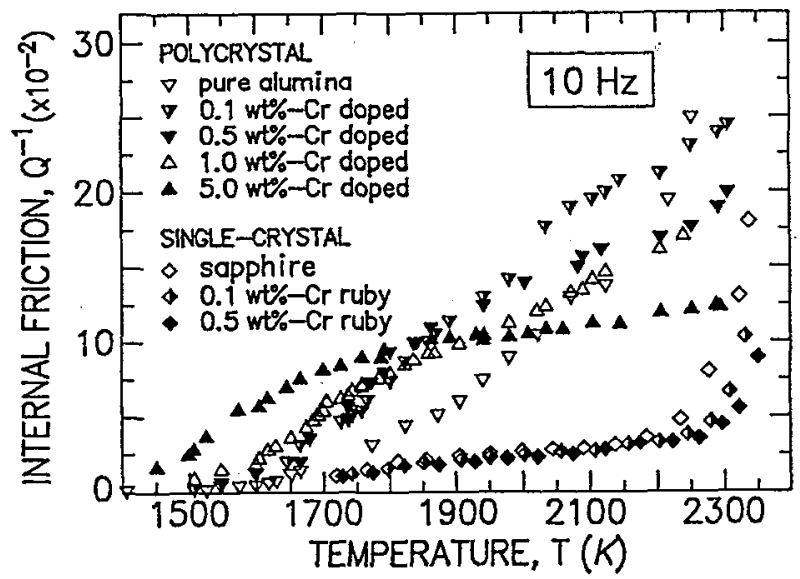

Figure 3: Internal friction curves of ruby single crystals and polycrystalline alumina-Cr solid solutions as a function of temperature. The curves were obtained at the frequency of $\approx 10 \mathrm{~Hz}$.

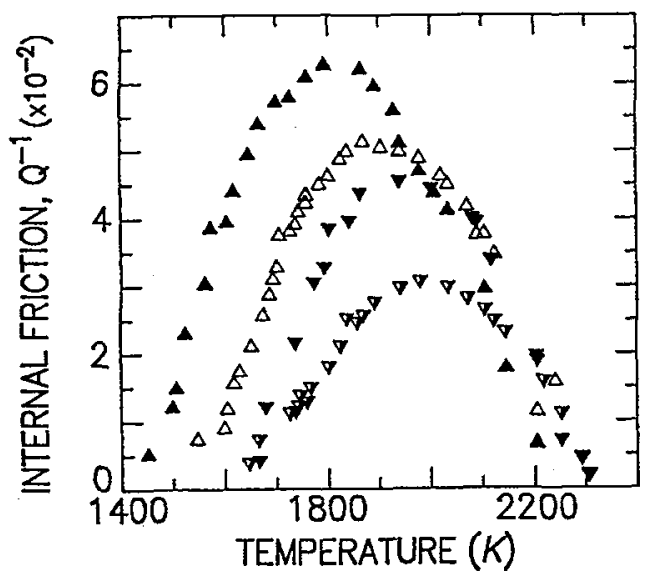

Figure 4: Evolution of grain-boundary relaxation peak in polycrystalline alumina upon increasing the amount of $\mathrm{Cr}$ in solid solution. 